\title{
Modern aspects of disturbed land reclamation
}

\author{
Natalia Antoninova ${ }^{1,2^{*}}$, Lyubov Shubina ${ }^{1}$, Artem Sobenin ${ }^{1,2}$ and Albert Usmanov ${ }^{2}$ \\ ${ }^{1}$ Federal state institution of science Institute of mining of the Ural branch of the Russian Academy of \\ Sciences, Yekaterinburg, Russia \\ ${ }^{2}$ Federal state budgetary institution of higher professional education Ural state mining University, \\ Yekaterinburg, Russia
}

\begin{abstract}
Annotation The urgency of solving environmental problems of disturbed territories is obvious in connection with the accumulation of a huge amount of waste from mining and metallurgical industries, deposited in slime and tailings dumps, overburden dumps, slags and substandard raw materials. Environmental rehabilitation of such territories is determined by both the possible long-term existence of such objects and the prospect of their reuse. In this regard, the use of new geosynthetic materials, the most promising and effective method of restoring ecological characteristics of the areas of violations of land, based on the implementation of the principle of least possible scope of application of topsoil and vegetation established, carrying out sanitary-hygienic function, contributes to the improvement of the environment in the areas of enterprise functioning. The article presents the results of applied research on the reclamation of the horizon the shortage of topsoil, or when you use the fertile layer, exposed to long-term storage in dumps. And the planting of grass vegetation on the recultivated surface that corresponds to the regional nature of environmental optimization measures, taking into account zonal features, will ensure the creation of sod that stops the processes of deflation and water erosion.
\end{abstract}

\section{Introduction}

The result of active development of mineral deposits was the formation of a fairly large number of dumps, warehouses, and storage facilities for enrichment waste. The world's experience in reclamation of disturbed lands is less than a hundred years old, and the first works were carried out in the United States (1926) on sites disturbed by mining operations. Reclamation was widely developed in Europe and the United States in the pre-war years and mainly after World War II. In the Russian literature, the term "reclamation of territories" first appears in 1962 (in the work of I. V. Lazareva, who highlighted the foreign experience of reclamation and considered this problem in relation to the use of disturbed land for urban development purposes). More than 50 years ago, zoning of reclamation activities in the country was developed [1]. One of the first works on reclamation in Russia should be considered the development of peat workings in the North and North-West of the European part of the country for forestry purposes [2]. The urgency of solving environmental problems of disturbed territories through their reclamation is obvious due to the accumulation of a huge amount of waste from mining and metallurgical industries [3-6].

\footnotetext{
${ }^{*}$ Corresponding author: natal78@list.ru
} 
Restoration of disturbed land is quite a long process, and the choice of areas for reclamation depends on many factors, in particular through artificial restoration of vegetation cover.

One of the most difficult objects for reclamation is tailings and sludge storage facilities of non-ferrous and ferrous metallurgy enterprises, which are accumulative formations that have arisen as a result of waste storage on the ground surface. The surface layer of tailings and sludge deposits contains up to $100 \%$ of particles with a diameter of less than $1 \mathrm{~mm}$. The soils that make up waste disposal facilities should be classified as bulk or alluvial artificial soils according to the General classification of soils.

Self-healing of these objects is almost non-existent for many years. Therefore, after the end of operation, reclamation, in order to eliminate their harmful impact on the environment, becomes an integral part of environmental protection measures. The solution to this problem is to create a cover that could perform anti-erosion functions and would be sufficiently stable and durable.

Therefore, the choice of the direction and technology of reclamation provides:

- creation of an ecologically, aesthetically and sanitary - hygienic area that is compatible with the border landscape;

- creating a soil layer on recultivated areas with a sufficient level of fertility;

- creation of vegetation cover on reclaimed land that corresponds to the direction of use.

In addition, the agrochemical properties of the applied reclamation layer are an important characteristic when developing methods for recultivation of disintegrated dump rocks. The conducted research [9] shows that the use of the method of reclamation layer using large volumes of potentially fertile rocks and soil cannot be recognized as universal, in particular in areas with a deficit of the fertile layer (PS) of the soil, or when using PS subjected to long-term storage in dumps, so when developing methods of waste reclamation in recent years, technology developers proceed from the principle of minimal land use.

Recently, it is proposed to use geosynthetic materials for the reclamation of the abovementioned objects. The main part of the underlying coatings in this case is a geosynthetic membrane with a thickness of 0.5 to $3.0 \mathrm{~mm}$. More complex coating systems may consist of several membrane layers, between which layers of geosynthetic clay, geotextile, reinforcing geogrids and synthetic drainage materials are laid. Usually, flexible geomembrane coating panels are welded together at the customer's installation site using either fusion (hot wedge) or extrusion.

After laying and leveling the geopoloten, it is necessary to lay a protective surface layer of soil, lay a protective geotextile, or fill it with a mineral layer or fine-grained sand. At the final stage, a drainage layer is applied, then a reclamation layer Man-made array (Fig. 1).

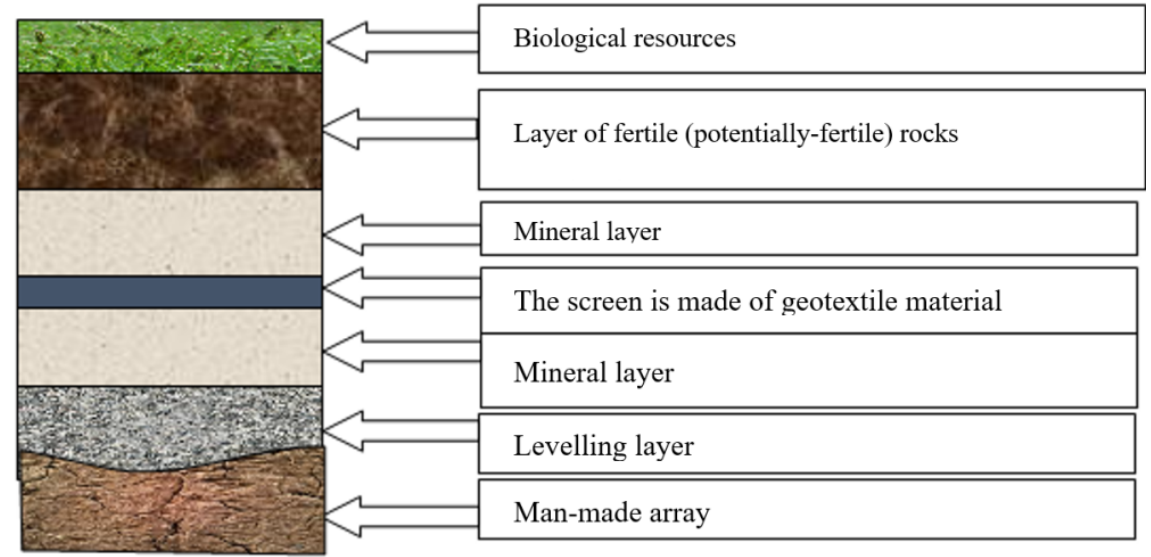

Fig. 1.Diagram of the screen formation with the creation of a reclamation layer 
Advantages of geosynthetic products:

- they have the same performance qualities as traditional materials, but allow you to get a more compact size of soil structures;

- allow you to save more rare and valuable natural resources.

Biological remediation as a process of optimizing technogenic complexes, should be carried out taking into account zonal features and, in General, correspond to the regional nature of environmental optimization measures. At the same time, it is necessary to take into account the negative changes that occur in natural systems that are specific to each natural zone due to their interaction with production systems.

\section{Main part}

One such example is the already liquidated sludge field of PJSC SinTZ, which is located on the Northern outskirts of Kamensk-Uralsky, Sverdlovsk region, adjacent to the industrial zone of the company "Sinarsky pipe plant", which is located on the territory of the Sinarsky planning district of the city. According to the official portal, there are 20 waste disposal facilities with a total area of 547.14 ha on the territory of the city of Kamensk-Uralsky. Waste disposal facilities are operated by 9 business entities. The maximum amount of waste is formed by the following economic entities: RUSAL Kamensk-Uralsky (mineral slurries), PJSC SinTZ (oiled scale), JSC KUMZ (aluminum-containing waste).

The liquidated sludge accumulator Synthesis is an open-pit mining in natural alluvialdeluvial clays. In the developed bowl, industrial waste is stored: various types of slime and slags (in places), covered with a layer of clay soil, moved to the liquidated sludge field after its excavation from the pit of the then-under-construction map No. 1 of the current sludge collector. It should be noted that the elimination of the sludge field was probably carried out without a project.

According to engineering surveys conducted at the reclamation site, the sludge is sediment formed during sedimentation in the sludge maps of the waste water of the etching production of the rolling workshops of the plant. Freshly deposited sediments in the initial stage of lithification undergo various transformations and transformation into sedimentary rock. The leading process in their transformation is gravitational compaction, accompanied by precipitation dehydration. In addition to self-sealing of the sludge, it is affected by the external load from the weight above the laid soil. In addition, when filling the maps (layerby-layer or front-by-side), the clay soil was deposited into the slurry substance, their mixing and substitution took place.

However, even liquidated slurry field and is located outside of the sanitary protection zones and the formation of reserves, existing water intakes, according to the hydrogeological conditions of the studied area, discharge of groundwater occurs in local streams and ponds (swamp Makulinski and R. Pozarica). Groundwater supply in the area under consideration is due to infiltration of precipitation and leaks from man-made objects through the aeration zone.

The choice of the direction of reclamation, which determines the regulations for the necessary work, is made in accordance with the requirements of GOST and the Decree of July 10, 2018 N 800 "on land reclamation and conservation", taking into account:

A) Natural conditions of the area where the object is located;

In the latitudinal-zonal plan of vegetation conditions, the territory described is located in the TRANS-Ural forest-steppe zone. All forests are derived. The composition of the rocks is dominated by aspen-birch forests with an admixture of pine. The vegetation cover of the survey area is represented, respectively, by meadow and forest-steppe formations. In the structure of the soil cover of Kamensky district, the leading place is occupied by a combination of chernozems, gray forest, gray gley, meadow and meadow-marsh soils. 
Limited distributions are combinations-mosaics of gray forest soils and chernozems with neighbors and with Solonets meadow-Chernozem. The dominant spots are leached and podzolizedchernozems. They lie on the lower third of the slopes, and the raised areas of the watersheds are occupied by gray soils.

B) The actual state of the disturbed territory.

The technogenic landscape with a total area of 10.5 ha is a fairly uneven surface with a large elevation difference from +177 to 181 . In the basin in the Northern part of the site, a surface reservoir was formed; the area of the water surface mirror is about $4400 \mathrm{~m}^{2}$. The surface was overgrown with grass and shrubby vegetation. The design documentation for the device of the sludge field is missing for years.

C) Geographical location. The sludge storage facility is located in close proximity to the industrial site of PJSC SinTZ and the existing sludge field, the impact of which on the territory will be manifested during the entire period of its operation, in addition, the reclamation site is located within the boundaries of the sanitary protection zone of PJSC SinTZ.

In addition, when choosing the direction of reclamation, the need for a number of technical measures was taken into account in order to create an anti-filtration screen that excludes a negative impact on the environment, namely, the leaching of pollutants from the body of the liquidated sludge field during the infiltration of precipitation. Due to the absence of clay quarries with the required filtration coefficient in the area of work, it was decided to provide a protective anti-filtration screen on the surface of geosynthetic materials (geomembrane) in the technology of the planned reclamation works. Based on this, the transit flow from precipitation will not occur after the technical stage of reclamation works is completed in full.

Thus, the creation of an anti-filtration screen using geosynthetic materials provided by the project will provide reliable protection against filtration of surface water into the body of accumulated slime and underlying soils. At the biological stage of remediation, a set of measures is envisaged to restore the agrochemical and physical properties of the soil sufficient for the creation and sustainable existence of vegetation cover. Grass vegetation, being one of the essential structural components of the landscape, performs a soil protection and sanitary-hygienic function. In connection with the above, the following species were included in the range of perennial grasses: Timothy-grass, cocksfoot, red clover, Kentucky bluegrass, fescue, field, forage legumes. Selected for the biological stage of reclamation, the grasses that are most adapted to local conditions and more resistant to adverse effects are able to grow quickly after mowing and create a closed herbage and strong turf.

Another example that illustrates the possibility of applying technology minimum loam with the use of geosynthetic materials is reclamation of tailings pond 1-queue Urupskiy GOK, which is situated in Urupskiy district, $1.4 \mathrm{~km}$ north of the village Mednogorskiy, in the valley of river Bagachwa and intended for the storage of solid waste enrichment (tails) of chalcopyrite ores (Fig. 2). Currently, it is filled up to the design marks and is subject to reclamation.

When developing remediation measures, the choice of the direction that determines the schedule of necessary work was made in accordance with GOST requirements, taking into account:

A) Natural conditions of the area where the object is located. The area where the remediation facility is located is mostly pine forests. The main soils of the district are mountain gray, dark gray and brown soils. In their profile, the total thickness of which rarely exceeds $80 \mathrm{~cm}$, under the forest floor $(1-5 \mathrm{~cm})$ lies a grayish-brown humus horizon $(0-15 \mathrm{~cm})$, containing from $6 \%$ to $15 \%$ of humus; 


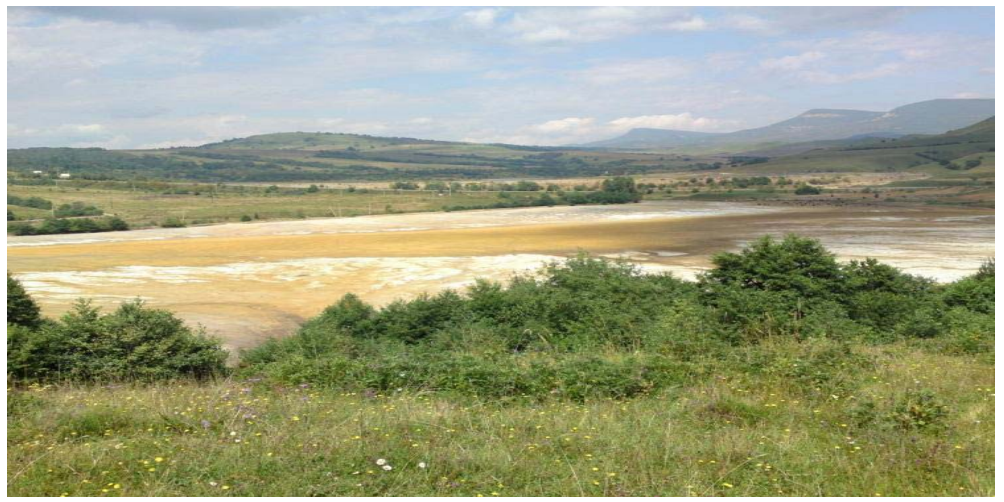

Fig. 2. Surface of the tailings dump

B) The actual state of the disturbed territory the currently used tailings dump with a total area of 97.2 ha is a flat surface of ash-gray color (Fig. The surface is completely devoid of vegetation. Individual instances are registered only on the field-dam border. An assessment of the natural vegetation on the surface of the tailings pond shows that plant settlement occurs only on contact with the mineral and plant soil of the dam;

C) The need for environmental optimization of the landscape.

When choosing the direction of reclamation, it was taken into account that the environmental and sanitary direction of reclamation is a series of technical measures to normalize the concentration of dust in the source area to the values provided for by the standards (GN 2.1.6.1338-032. Maximum permissible concentrations (MPC) of pollutants in the atmospheric air of populated areas, SanPiN 2.1.6.1032-01. Hygienic requirements for ensuring the quality of atmospheric air in populated areas), improving the aesthetic perception of an object with disturbed land relief.) At the same time, the accumulation of precipitation and its filtration through the tailings of the processing plant containing heavy metals and metalloids such as: cadmium, zinc, lead, nickel, copper, mercury, arsenic without taking appropriate measures will turn the tailings of stage I into a source of contamination of surface and underground waters. Currently, the choice of the direction of reclamation is also influenced by the assessment of large-capacity enrichment waste as a man-made deposit. According to the research [10], it is advisable to consider the tailing dump of the first stage of the Urupsky GOK from this position (table 1).

Table 1. Content of precious metals in tailings samples $(\mathrm{g} / \mathrm{t})$

\begin{tabular}{|c|c|c|c|}
\hline Element & From & To & Average \\
\hline $\mathrm{Au}$ & 0,49 & 10,9 & 1,96 \\
\hline $\mathrm{Ag}$ & 11,0 & 23,6 & 17,2 \\
\hline $\mathrm{Pt}$ & $<0,04$ & $<0,04$ & $<0,04$ \\
\hline $\mathrm{Pd}$ & $<0,03$ & $<0,03$ & $<0,03$ \\
\hline $\mathrm{Re}$ & 0,028 & 0,091 & 0,051 \\
\hline
\end{tabular}

Orientation to the temporary nature of vegetation cover also changes the approach to landscape assessment of this type of technogenic disturbances. There is no need to consider it as a structural unit of the new landscape, and, consequently, the need to complicate the created phytocenosis.

This factor also leads to a change in the technology of formation of the reclamation layer. In relation to objects where reclamation will be temporary, it is most appropriate to proceed from the principle of minimal land use or the use of other substrates available in specific conditions. In this regard, rehabilitation measures should include not only the elimination of environmental pollution after the end of its operation, but also the possibility of fairly easy in the future involvement of laid tailings in the process of mining. 
When choosing the direction of reclamation, the following was also taken into account:

The phase I tailings storage facility is adjacent to the new phase II tailings storage Facility, which will have an impact on the reclaimed area over the entire period of its operation.

The tailings storage area is located in the immediate vicinity of the station. This is why it is recommended to turn the site into a sanitary protection zone.

Requirements for land reclamation in the sanitary and hygienic direction of remediation of the tailings pond surface include creating a screen of capillary-breaking or neutralizing materials in the presence of toxic rocks at the base of the reclamation layer and applying a fertile or potentially fertile layer to the horizontal surface.

Measures for the biological stage of reclamation are aimed at creating favorable conditions for the restoration of the plant community characteristic of the area.

\section{Conclusions}

Thus, the feasibility of temporary reclamation of technogenic mineral formations using the principles of minimal land use is obvious, and the created vegetation cover performs the function of sanitary and hygienic, contributing to the improvement of the environment for the entire period of possible re-development of the technogenic deposit.

The research was supported by the Ministry of Science and Higher Education in accordance with the state assignment for Ural State Mining University No. 0833-2020-0008 'Development and environmental and economic substantiation of the technology for reclamation of land disturbed by the mining and metallurgical complex based on reclamation materials and fertilizers of a new type'. We obtain the scientific results with the staff of Center for the collective use by using funds of the Center for the collective use of scientific equipment of the Federal Scientific Center of biological systems and agricultural technologies of RAS as well (No Ross RU.0001.21 PF59, the Unified Russian Register of Centers for Collective Use -http://www.ckp-rf.ru/ckp/77384).

\section{References}

1. L.Motorina, G. Zaitsev, Physical geography,4, 16-17 (1970)

2 K.Nazina, Scientific Bulletin of Moscow state University,12(45), 131-138 (2013)

3 N.Antoninova, L. Shubina, News of higher educational institutions, GornyZhurnal,8, 6468 (2013)

4 L.Rybnikova, P. Rybnikov,Materials of annual session of RAS Scientific Council on problems of Geoecology, engineering Geology and hydrogeology,91-96 (RUDN, Moscow 2018)

5 A.Khokhryakov, E. Zeitlin, Proceedings of the Samara scientific center of the Russian Academy of Sciences,14(1-3), 834-837 (2012)

6 I.Tyabotov, N. Grevtsev, L. Oleinikova, A.Gorbunov,Agri-food policy of Russia,5,41-46 (2018)

7 G.Chaikina, V.Obedkova,Recultivation of disturbed land in the mining areas of the Urals (2003)

8 E.Alampieva V., E.Panova,Izvestiya RGPUim. A. I. Herzen,154, 115-122 (2013) 